\title{
Atrial fibrosis progression in patients with Atrial Fibrillation
}

\author{
Robert B White*, Mohamed Labedi, Jordan King, Christina F Pacchia, Kara Johnson, Gagandeep Kaur, Joshua Cates \\ , Alan Morris, Nassir F Marrouche \\ From 19th Annual SCMR Scientific Sessions \\ Los Angeles, CA, USA. 27-30 January 2016
}

\section{Background}

Fibrosis is a hallmark of arrhythmogenic structural remodeling in patients with Atrial Fibrillation (AF). Recently, the degree of atrial fibrotic changes has been correlated with stroke and poor treatment outcome in patients with AF. In this study, we report temporal behavior of atrial fibrosis.

\section{Methods}

Eighty-eight patients (58\% male, mean age $60.4+/-14.7$ ) with AF who underwent late gadolinium enhancement MRI (LGE-MRI) to assess the degree of atrial tissue fibrotic changes were included in this study. All patients underwent at least 2 or more LGE-MRI separated by more than 3 months of follow up. Progression of fibrosis was defined as an increase in fibrosis area by more than $5 \%$ (Figure 1). Demographic patient data as well as comorbidities and medications were collected from chart revisions.

\section{Results}

A total of 32 patients (36.4\%) had hypertension, 21 (23.9\%) with hyperlipidemia, 9 (10.2\%) with diabetes, 6 (6.8\%) patients had with a history of tobacco abuse and $10(11.4 \%)$ with coronary artery disease. A total of 38 (43.2\%) patients were on statin, 25 (28.4\%) were on angiotensin converting enzyme inhibitor, 36 (40.9\%) were on a beta- ${ }^{\circ} \odot$-blocker, $31(35.2 \%)$ were on anticoagulant, and $13(14.8 \%)$ were on antiarrhythmic medication. Subsequent follow- ${ }^{\circ} \odot$-up MRIs were performe on $32(36 \%)$ patients that exhibited progression of atrial fibrosis.

Using univariate logistic regression models we were not able to identify significant predictors of fibrosis

Cardiovascular Center, University of Utah Hospital, Providence, UT, USA progression. The majority of patients (64\%) did not reveal any significant changes from the initial quality and quantity of atrial fibrosis at 1 year MRI follow-up.

\section{Conclusions}

Atrial fibrosis quantified by LGE-MRI seems to be stable in a majority of AF patients at one-year follow-up. Approximately a third of patients evaluated exhibit progression of atrial fibrotic disease. A means to alleviate progression in this population would improve surrogate outcome.

Published: 27 January 2016

doi:10.1186/1532-429X-18-S1-P149

Cite this article as: White et al:: Atrial fibrosis progression in patients with Atrial Fibrillation. Journal of Cardiovascular Magnetic Resonance 2016 18(Suppl 1):P149.
Submit your next manuscript to BioMed Central and take full advantage of:

- Convenient online submission

- Thorough peer review

- No space constraints or color figure charges

- Immediate publication on acceptance

- Inclusion in PubMed, CAS, Scopus and Google Scholar

- Research which is freely available for redistribution 